Original Article

\title{
Anxiety \& Coping Patterns Regarding Pubertal Changes among Pre-Adolescent Girls of Udupi Taluk, Karnataka
}

\author{
Sequeira D.F. ${ }^{1}$, D'souza $A_{1}{ }^{2} \&$ Sanatombi Devi E. ${ }^{3}$ \\ ${ }^{1}$ Post graduate, ${ }^{2}$ Assistant professor, ${ }^{3}$ Professor \& HOD, Department of M edical Surgical Nursing, \\ Manipal College of Nursing Manipal, M anipal University, Karnataka, India. \\ Correspondence \\ Anjalin D'Souza \\ Assistant professor, Manipal College of Nursing Manipal, Manipal University. \\ E-mail : anjeline.d@manipal.edu
}

\begin{abstract}
Background : Puberty is a period in the developmental span when the individual changesfrom an asexual being to a sexual being.

Objectives : The present study was aimed to assess the anxiety and coping pattern regarding pubertal changes among pre-adolescents girls in selected schools of Udupi Taluk, Karnataka.

Materials and methods : The study included 540 pre-adolescent girls of age group (10-12years) from selected schools of Udupi Taluk by cluster random sampling technique. Data was collected using structured questionnaires.

Results : The study showed that out of 231 pre-adolescents who attained menarche $(55 \%)$ had moderate anxiety and $52.4 \%$ had adaptive coping pattern. Among 309 pre-adolescents who did not attain menarche, $62.1 \%$ had moderate level of anxiety and $53.4 \%$ had adaptive coping pattern regarding pubertal changes. It also showed that there was a negative correlation between anxiety and coping pattern of the pre-adolescent girls, $r=-0.754$.
\end{abstract}

Conclusion : The study concluded that pre-adolescent girls have moderate level of anxiety and adaptive coping pattern regarding pubertal changes and it also showed that when anxiety increases coping pattern decreases. M ajority of the respondents had moderate level of anxiety and adaptive coping pattern.

Keywords: Anxiety, puberty, coping pattern, pre-adolescents.

\section{Introduction}

Puberty is a period in the developmental span when the individual changes from an asexual being to a sexual being. It is a period of rapid physical change and personality growth when individual achieves nearly the adult bodily stature. The girls begin their preadolescent growth spurt at about 10 years of age and boys at about 12 years of age. Girls and boys approach the end of puberty between 12-14 and 13-15years respectively. ${ }^{1}$

During puberty the biological changes reach a climax and

Access this article online Quick Response Code

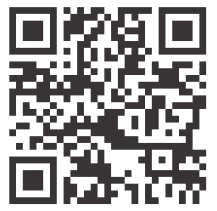
there is sexual maturity in both boys and girls. The pubescent girls and boys will have more concern about their bodily about psychological consequences. Among changes, which will bring many adjustments the adolescents must make, the most important is learning about the change in the body. With the onset of puberty the feeling, questions and concern about bodily appearance begin to occupy a central place in the life of the individual. All physical characteristics require extraordinary attention and examination during this phase. This is a time, which the individual feels himself different from others and undesirable characteristics put the adolescent at risk for teasing and redicule. ${ }^{2}$

Adolescence is regarded as unique phase of human development; adolescents are important resources of any country. They have successfully passed the adversaries of early childhood and are on the way to adulthood. ${ }^{3}$

Adolescence is a period where a vital physical and psychosexual change takes place. In this regard, not only the preschooler, but also the older child that is the preadolescents between the age of 10 and 12 years should 
also receive adequate attention as a preparation for pubertal changes and menarche. ${ }^{4}$

A correlative study to assess the knowledge and anxiety of pre-adolescents related to pubertal growth in a selected school of Udupi district among 170 pre-adolescents showed that $55.88 \%$ had not received adequate parental preparation on pubertal growth , $61.8 \%$ had only average knowledge and majority 154 (90.58\%) had moderate anxiety of which 83 were girls and 71 were boys. The data also showed that $16(9.41 \%)$ had severe anxiety of which 8 were girlsand 8 were boys. ${ }^{4}$

Kumar et al investigated 1000 girls and boys of the age group 13-19 years drawn from eight selected institutions to determine the pattern of anxiety related to their own growth during puberty at Punjab. The study results showed that a larger number of subjects were needlessly troubled on account of viewing the normal variations in the rate of physical development as abnormal variations. Boys surpassed girls in the degree of concern expressed over various parameters of pubertal growth and development. Height, shoulder width, and pubic hair growth were the principal areas of concern in boys and menstruation, height and weight in girls. ${ }^{5}$

A descriptive comparative study in Punjab about knowledge and coping patterns among 200 adolescents regarding pubertal changes showed that most of the adolescents were having good knowledge. As per comparison, female adolescents (72\%) were having better knowledge than male adolescents (68\%). In terms of coping, male adolescents (92\%) had more adaptive coping patterns than female (22\%) adolescents. The study concluded that there is a need to educate the adolescents especially females regarding pubertal changes before the onset of puberty. This may improve their coping ability in future and can lead a healthy life. ${ }^{6}$

Mehta M, Chugh $G$ and Pandey $P$ investigated developmental changes and gender differences in the experience of stress and coping strategies among children. About 2000 school children in the age of 8-14 years from different schools of Delhi were administered scales to measure physical and psychological symptoms of stress, stressful life events as well as their coping strategies. The study revealed that females had higher physical as well as psychological manifestation of stress and had somewhat higher levels of daily hassles contributing to their stress and girls make more use of seeking social support and problem solving as coping strategies when compared to boys. The study concluded that females are at higher risk of taking stress and they are more anxious about the changes occurring in their body.

Studies have shown that there is lack of adequate information about pubertal changes and parental guidance to meet with changes in pubertal period. This leads to anxiety and misconceptions in the mind of young adolescents especially females which hinders their healthy growth. The purpose of the study was to assess the anxiety and coping pattern regarding pubertal changes among preadolescent girls and to provide an informational pamphlet which will help to reduce the anxiety and to improve the coping pattern and adaptation in future.

The objectives of the study were to assess and determine the relationship between anxiety and coping pattern regarding pubertal changes among preadolescent girls who attained and did not attain menarche.

\section{Material and M ethod}

The conceptual framework adopted for the study was Betty Neuman's System M odel. ${ }^{8}$

Descriptive survey was adopted and study setting was higher primary schools of Udupi Taluk.

Cluster random sampling was used to select the schools .Study was conducted among 540 girls from 12 higher primary schools. The sample size was calculated at $95 \%$ confidence interval. The related precision was taken at $2 \%$. The divisions of classes $5^{\text {th }}, 6^{\text {th }}$, and $7^{\text {th }}$ are considered as clusters and samples were all the female preadolescents in the selected division who met the sampling criteria. Ethical permission was obtained from Institutional Ethics Committee. Assent from the participants was obtained and 
parents' consent was taken prior to the study. Confidentiality of the information provided by the respondents was assured to them by taking down the roll numbers.

\section{Data collection instruments}

Tool 1 : Demographic proforma: It included 15 items regarding background information. Items included were age, class of study, educational and occupational status of the parents', birth order, family income, source of information and attainment of menarche.

Tool 2 : Anxiety scale was developed by the researcher. It consists of 33 items in which 4 items were exclusively for the pre-adolescents girls who attained menarche. It was a 3 point rating scale with three alternatives never, sometimes, always. A score of 69 to 87 was considered as severe anxiety, 49 to 68 as moderate anxiety and 29 to 48 as mild anxiety. To ensure the content validity it was given to 9 experts from the field of mental health nursing, child health nursing and OBG nursing. Reliability was computed using Cronbach's Alpha and r was 0.76 .

Tool 3: Coping scale consists of 29 items regarding various coping pattern adopted by the pre-

adolescents. The areas selected were self-acceptance, avoidance, spiritual-positive coping, seeking social support and positive reappraisal. It was 4 point likert scale with four alternatives namely strongly agree, agree, disagree and strongly disagree. To ensure the content validity it was given to 9 experts from the field of mental health nursing, child health nursing and OBG nursing. Reliability was computed using Cronbach's Alpha and r was 0.71.A score between 73 to 116 were considered as adaptive coping pattern and 29 to 72 as maladaptive coping pattern.

Tool 4 : Opinionnaire regarding informational pamphlet provided to the participants. It consisted of 10 items to get their opinion on informational pamphlet.

The data was collected from the samples and then informational pamphlet was distributed to all the samples.
The statistical analysis was done using SPSS version 16 . Frequency, percentage, chi-square and spearman's rho were the statistical tests used for the data analysis with the level of significance at 0.05 .

\section{Results}

\section{Sample characteristics}

Demographic profile of subjects is presented in Table 1.

Table 1: Frequency and percentage distribution of sample characteristics. $(n=540)$

\section{Sample characteristics}

1. Age in
A. 10
B. 11
C. 12
A. 10
B. 11

2. Class of study

A. 5

B. 6

C. 7

\section{ears}

(1)

\begin{tabular}{l|l}
170 \\
18
\end{tabular}

3. Father's educational status

A. No formal education

B. Primary

C. Secondary

D. Pre-university

E. Diploma

F. Degree \& above

4. Mother's educational status

A. No formal education

B. Primary

C. Secondary

D. Pre-university

E. Diploma

F. Degree $\&$ above

5. Father's occupation

A. Unemployed

B. Farmer

C. Business

D. Skilled

E. Professional

F. Semi skilled

6. Mother's occupation

A. House wife

B. Semi skilled

C. Business

D. Skilled

E. Professional

\section{Religion}

A. Hindu

B. Muslim

C. Christian \begin{tabular}{|l|l|l}
\hline Frequency (F) & Percentage (\%) \\
\hline
\end{tabular}

31.5

34.1

34.4

33.3

33.3

33.3

180

4.6

40.2

28.5

15.7

2

8.9

48

48

47

217

8.7

40.2

28.9

13.7

1.5

7




\begin{tabular}{l|c|c}
\hline Sample characteristics & Frequency (F) & Percentage (\%) \\
\hline 8. Type of family & & \\
A. Extended & 90 & 16.7 \\
B. Joint & 316 & 21.5 \\
C. Nuclear & & 61.9 \\
\hline 9. Birth order & 215 & \\
A. 1 & 232 & 49.8 \\
B. 2 & 71 & 13.1 \\
C. 3 & 22 & 4.1 \\
D. 4 \& above &
\end{tabular}

10. Total monthly family income in rupees
A. $<2000$
B. $2000-4000$
205
38.0
C. $4001-6000$
161
29.8
D. $6001 \&$ above
16.9
15.4

11. Source of health related information
A. News paper
B. Magazines
C. Radio
D. Television
E. Cinema
F. Computer/ Internet
G. Teachers
H. Friends

44

24

174

4

15

213

42
8.1

4.4

4.4

32.2

0.7

2.8

39.4

7.8

the sample. In majority of the respondents mother explained to them regarding menstruation/pubertal changes $454(84.1 \%)$. Majority of the respondents have not attained the menarche $309(57.2 \%)$ and majority who attained menarche are at the age of 11 years, $98(18.1 \%)$.

Anxiety : Results showed that out of 231 pre-adolescents who attained menarche, 15(6.5\%) had severe anxiety, 127 (55\%) had moderate and $89(38.5 \%)$ had mild anxiety.

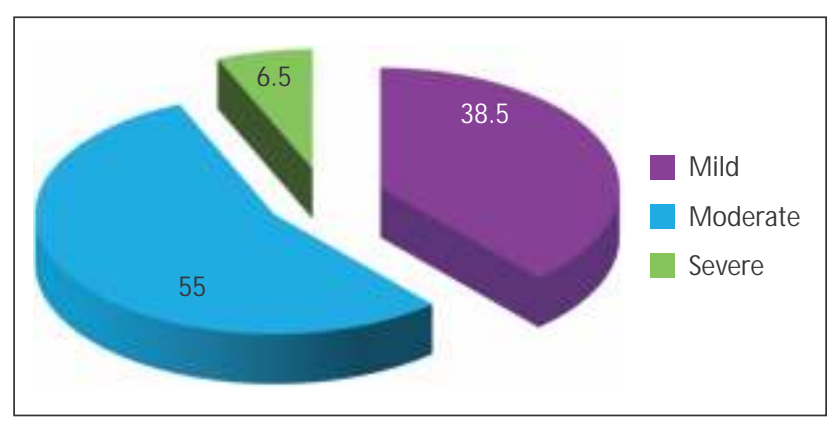

Fig 1(A) : Pie chart showing percentage distribution of anxiety scores of preadolescents girls who attained menarche It also showed that out of 309 pre-adolescents who did not attain menarche, 35(11.3\%) had severe anxiety, 192 (62.1\%) had moderate and 82 (26.5\%) had mild anxiety.

12. Does your mother explain to you about menstruation/ pubertal changes

A. Yes

B. No

13. Specify the source of information regarding menstruation.
A. Mother
B. Sibling
C. Friends
D. Father
E. Neighbour
F. No information

14. Have you attained menarche
A. Yes
B. No
231
309
42.8
57.2

15. If yes, when did you attain? (mention the age at menarche)
A. 10
B. 11
39
16.88
C. 12
98
42.42
40.69

The data presented in table 1 reveals that out of 540 samples, $186(34.4 \%)$ respondents were in the age group of 12 years. With respect to parents' educational status, primary education comprised of highest percentage $217(40.2 \%)$. In majority of the respondents father's occupation was semiskilled type and mothers were housewives, 345 (63.9\%). Considering the data on religion most of the respondents were of Hindu religion $359(66.5 \%)$ and majority of the respondents were from nuclear family $334(61.9 \%)$. With regard to data on birth order most of the respondents belong to $2^{\text {nd }}$ birth order $232(43.0 \%)$. In majority of the respondents total monthly income is $<2000,205(38 \%)$. Teachers $213(39.4 \%$ ) were the source of information for most of

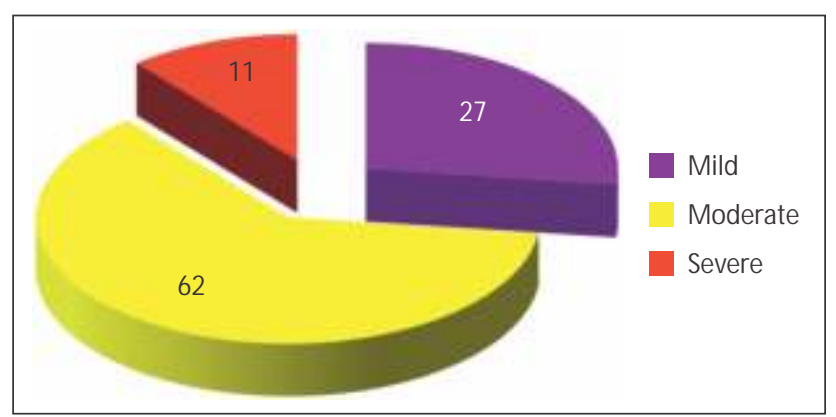

Fig 1(B): Pie chart showing percentage distribution of anxiety scores of preadolescents who did not attain menarche

\section{Coping pattern}

Out of 231 female pre-adolescents who attained menarche, 121 (52.4\%) had adaptive coping pattern and $110(47.6 \%)$ had mal adaptive coping pattern regarding pubertal changes. Out of 309 female pre-adolescents who did not attain menarche, 165 (53.4\%) had adaptive coping pattern and 144 (46.6\%) have mal adaptive coping pattern regarding pubertal changes.

\section{Correlation between Anxiety and Coping pattern}

Spearman Rho Correlation coefficient was computed between anxiety and coping pattern of pre-adolescents who attained and who did not attain menarche. It was evident that there was a significant relationship between 
anxiety and coping pattern of pre-adolescents in both the groups respectively $(r=-0.754, p=0.001), \quad(r=-0.675$, $\mathrm{p}=0.001$ )

Table 2(A) : Correlation Co-efficient computed between anxiety and coping pattern of female pre adolescents regarding pubertal changes who attained menarche.

$(n=231)$

\begin{tabular}{|l|l|c|}
\hline Variables & r Value & p Value \\
\hline Anxiety Coping & $-0.754^{*}$ & .001 \\
\hline
\end{tabular}

The data presented in table 2(A) shows that the correlation co-efficient of anxiety and coping pattern score of female pre adolescents who have attained menarche is $(-0.754)$.

Table 2(B): Correlation Co-efficient computed between anxiety and coping pattern of female pre adolescents regarding pubertal changes who did not attain menarche

$(n=309)$

\begin{tabular}{|l|l|c|}
\hline Variables & r Value & p Value \\
\hline Anxiety Coping & $-0.675^{*}$ & .000 \\
\hline
\end{tabular}

The data presented in table 2(B) show that the correlation co-efficient of anxiety and coping pattern score of female pre adolescents who did not attain menarche is (-0.675).

\section{Other findings of the study}

Opinionnaire on informational pamphlet was collected and it showed that majority of the pre-adolescent girls (77.4\%) believe to a great extent that information pamphlet on pubertal changes is a good source of learning. Most of the respondents ( $71.7 \%)$ strongly felt to a great extent that the pamphlet is easy to understand.

\section{Discussion}

The study revealed that majority of $127(55 \%)$ the respondents who attained menarche had moderate level of anxiety and majority of the respondents 192 (62.1\%) who did not attain menarche also had moderate level of anxiety.

The findings of the present study is supported by a correlational survey conducted by Jilu M eera to assess the knowledge and anxiety of pre-adolescents related to pubertal growth in Udupi district among 170 preadolescents. Majority 154 (90.58\%) had moderate anxiety of which 83 were girls and 71 were boys. The data also showed that $16(9.41 \%)$ had severe anxiety of which 8 were girls and 8 were boys. ${ }^{4}$
The present study revealed that majority of 121 (52.4\%) the respondents who attained menarche had adaptive coping pattern and majority of the respondents 165(53.4\%) who did not attain menarche also had adaptive coping pattern. Whereas, study by Vibha in Punjab revealed that male adolescents (92\%) had more adaptive coping patterns than female (22\%) adolescents. ${ }^{6}$

The findings of the present study show that there is a negative correlation between anxiety and coping pattern score of pre adolescents girls who have attained $\&$ not attained menarche $(-0.754),(-0.675)$.

The findings were supported by similar study conducted by Bruce and Byrne. This study investigated the relationships between anxiety, fear, self-esteem, and coping strategies in a sample of 224 post primary students (years 7, 9, and 12) in Australia. There was a significant correlation $(p<.01)$ between anxiety and fear for both the boys and the girls at year $7, r(34)=.49$ and $r(36)=.50$, respectively, and at year $12, r(36)=.54$ and $r(38)=.52$, there was none at year 9 . Furthermore, for both the boys and the girls at year 12 , there was a significant $(p<.01)$ negative correlation between self-esteem and anxiety, $r(32)=-.69$ and $r(32)=$ .67 , and between self-esteem and fear, $r(31)=-.45$ and $r(31)=-.68$. It is noteworthy that there was a stronger correlation between self-esteem and fear for the girls than for the boys at year $12 .{ }^{9}$

The current study was limited to adolescents girls between 10-12 years of age studying in $5^{\text {th }}, 6^{\text {th }}$ and $7^{\text {th }}$ grade in selected schools of Udupi Taluk.

\section{Conclusion}

The study concluded that majority of the respondents had moderate level of anxiety and adaptive coping pattern. The findings revealed a significant negative correlation between anxiety and coping pattern. Hence it is concluded that higher the anxiety score, lesser will be the coping pattern and lesser the anxiety higher will be the coping pattern. Most of the respondents felt that the informational pamphlet provided to them is the good source of learning and easy to understand. 
Adolescents belong to a very vital age group as they are the entrant population to parenthood. These groups undergo vital physiological and psychosexual changes. So the preadolescents should receive adequate attention as a preparation to meet the changes in the adolescent period.

\section{References}

1. Marlow D. Textbook of Pediatric Nursing. Tokyo. W.B. Sounders Company.2005

2. Rutter M, Taylor E, Hersov L. Child and Adolescent Psychiatry. London: Blackwell Scientific Publications.2005

3. Parwej S. Reproductive Health Education intervention trial. Indian Journal of Paediatrics. 2005; 72(1) 134-142

4. Jacob J. A study to assess the knowledge and anxiety on pubertal changes among adolescents in selected schools of Udupi dist. Unpublished Master of Nursing Thesis. 2002; Manipal University.

5. Kumar et al. Adolescent Anxiety related to pubertal growth and development. Indian Journal of pediatrics.1987. 24(6), 481-487.

6. Vibha. Knowledge and coping patterns among adolescents. Nightingale nursing times.2010;6(9): 34-38

7. Mehta K. Developmental changes and gender differences in the experience of stress and coping strategies among children. Indian Journal of Psychiatry. 2007;49(2):34-45, ISSN 00195545; S43-S44

8. Betty Neuman's Systems M odel. Nursing Theories. British Jnl. For the Philosophy of Sci.1988[cited 2008 Jul 20]:available from :http://nursing theories .blogspot.in/2008/07/bettyneumans.html.

9. Bruce, Byrne. Relationship between anxiety, fear, self-esteem and coping strategies in pubertal development. Journal of Youth and Adolescence. ProQuest medical Library. 2000; 35(2):137-140. 